\title{
Towards an Understanding of Ecological Challenges of Second Language Teaching: A Critical Review
}

\author{
Masoud Mahmoodzadeh \\ Sheikhbahaee University, Isfahan, Iran \\ Email: masoudmahmoodzadeh@yahoo.com
}

\begin{abstract}
In an attempt to explore the ecological aspects of Second Language Teaching (SLT) Dilemma (Danesi, 2003), the present study aims at addressing the ecological challenges pervading in the realm of second/foreign language teaching over the last decades. To this end, the study seeks to trace the major theoretical reactions dealing with ecological challenges in the rich historiography of language teaching during the last two decades. In this regard, this article outlines a classified overview of the three perceptible trends to highlight the prevailing issues of contention and come up with some insights accordingly. The three scholastic trends are: (a) Post-Method approach; (b) 'In-Method' approach; and (c) Complexity approach. To elucidate the above trend-setting reactions, the researcher delves into their underpinning principles and assumptions to be able to juxtapose and compare them in a more meticulous fashion. The article also encompasses some concluding remarks which may shed light on the ecological panorama of second language pedagogy.
\end{abstract}

Index Terms - ecological challenges of second language teaching (SLT), SLT dilemma, ELT methodology

\section{INTRODUCTION}

\section{A. Ecological Aspects of Second Language Teaching (SLT) Dilemma}

Within the domain of second language pedagogy, a host of methods and approaches have been proposed over the last decades which have in large part contributed to the development of second language teaching. Nevertheless, in practice, they have not been sufficiently prosperous from a methodological perspective. In principle, doubt has always been cast on the pedagogical effectiveness of teaching practices, learning materials, and language syllabuses. In fact, as such methods and approaches have been launched into implementing their assumptions in the given teaching contexts; the vast majority of them have virtually failed to meet the expectations and satisfaction of their target language learners. This may indicate that the reality in all likelihood is still far from the ideal (Danesi, 2003; Mahmoodzadeh, 2011, 2012).

Given such language teaching crisis termed "Second language Teaching (SLT) Dilemma" by Danesi (2003), seemingly the socio-cultural forces sometimes accompanied by somewhat ideological changes, have played a pivotal role in the global landscape of English language teaching (ELT), since the central impacts of ecological constraints have almost pervaded in language teaching. To the author's knowledge, increasingly growing ethno-cultural and ecological challenges in the application of teaching methods and approaches can significantly account for the emergence of the SLT Dilemma as well as the neurolinguistically-oriented methodological challenges (see Danesi, 2003 for the neurolinguistically-based methodological explanation). By definition, in this study ecology generally refers to the study of biological organisms within the environment. At the innermost level of ecological factors, are the socio-cultural variables in which the participants and contexts are inextricably linked. In this sense, an ecological perspective on language teaching "focuses attention on the subjective reality which various aspects of the teaching-learning process assume for participants, and on the dynamic interaction between methodology and context" (Tudor, 2003, p. 1).

\section{B. The Advent of Ecological Challenges in the Domain of ELT Methodology}

In the circle of ELT, the infancy of methodological failures constrained by socio-contextual influences was not principally stressed until the predominant inception of communicative language teaching (CLT) which was established as a reaction to grammar-based teaching realized in the teaching materials, syllabi, and methods prevalent in the $1960 \mathrm{~s}$. Almost one decade after the heyday of CLT, however, researchers around the world began to observe and report the indication of socio-cultural barriers which adversely contrasted with the ideological underpinning of CLT methodology and thus significantly impeded the implementation of CLT in the given teaching contexts. According to Kumaravadivelu (2006a), one of the central claims of CLT as well as its offshoot, namely, task based language teaching (TBLT) is that it can be contextualized to meet various learning and teaching needs, wants, and situations. But advocates of both CLT and TBLT have been using the term context mainly to refer to linguistic and pragmatic features excluding the broader social, cultural, political, and historical particularities.

However, the vestige of these methodological challenges has been widely tracked down in various EFL settings around the world (e.g. Breen, 2006; Butler, 2005; Chowdhury, 2003; Savignon \& Wang, 2003; Shamim, 1996). To 
exemplify the materialized incongruities of methodologies with teaching contexts, some related to CLT are consider in the following: From South Korea, Li (1998) points to the difficulties in adopting CLT and attributes the source of the difficulty to the differences between the underlying educational theories of South Korea and Western countries. From China, Yu (2001) and $\mathrm{Hu}$ (2005) report considerable resistance to CLT both from teachers and learners. Likewise, Ellis (1994) questions the relevance of CLT in English language teaching by Australian teachers in Vietnam. He describes CLT as socially constructed with Western values such as individualism (versus what he calls collectivism in Vietnam) and, as such, not culturally attuned to Asian conditions.

Given the orthodox syndrome of the above ecological obstacles identified in ELT literature, some researchers, however, have embarked on delineating some possible resourceful remedies to confront these seemingly pedagogical challenges or constraints surfacing in different educational environments (see Bax, 2003; Bjorning-Gyde, Doogan, \& East, 2008; Ellis, 2005; Fenton \& Terasawa, 2006; Johnson, 2006; Kumaravadivelu, 1994, 2001, 2003a; LarsenFreeman, 1999; Pishghadam, 2011; Pishghadam \& Zabihi, in press). Nevertheless, note further that the widespread ecological constraints might have germinated in some of the feasible solutions as well. For instance, Howard and Millar (2009) investigated the applicability of Ellis's (2005) principles for successful instructed second language learning in South Korea and concluded that some ecological factors can hinder the effective implementation of these principles.

\section{The Classification of Approaches towards Ecological Challenges of Second Language Teaching}

To establish a sufficiently relevant background, the present study attempts to review the ecological aspects of SLT Dilemma over the last two decades. In doing so, the researcher surveys the three perceptible trends which have endeavored to tackle the ecological impediments: (a) Post-method approach (b) 'In-method' approach (c) Complexity approach. The study, then, gives some suggestions which might bring into language teaching research some insights.

\section{A. Post-method Approach}

Around the early 1990s, second language pedagogy witnessed some fundamental changes and innovations which led to the decline of the long-established method era. In this respect, Pennycook (1989), Prabhu (1990), Stern (1991), Richards (1990), and Kumaravadivelu (1994) were among the first iconoclasts who called the conceptual coherence and validity of method into question and upheld an anti-method position instead. In essence, this was a decade during which the supremacy of one method over another came to an end and the post method era emerged with a focus on how teachers could develop and explore their own teaching through reflective teaching and action research (Richards, 2002). As Richards and Lockhart (1994) note, the emergence of post-method pedagogy led to the revitalization of teaching from the inside rather than by trying to make teachers and teaching to conform to an external model.

In this approach, different frameworks and guiding principles have been tendered so far to provide support for teachers as they determine the microstrategies and teaching practices that are most appropriate for their individual contexts (see Allwright, 2003; Ellis, 2005; Kumaravadivelu, 2001, 2003a, 2006b; Lightbown, 2000; Richards, 2001). Given below is a brief account of the underlying tenets of Kumaravadivelu's (1994) post-method pedagogy as the most widely recognized pedagogical framework put forward for ELT teachers and practitioners.

\section{Post-Method Pedagogy}

Post-method pedagogy was perhaps one of the early attempts to resolve the ubiquitous spread of ecological challenges and constraints proliferating in the realm of second language pedagogy. According to post-method pedagogy, the pervious language teaching methods have been developed and prescribed for use based on a set of over-generalized methodological tenets. Therefore, they have failed to fulfill teachers and learners' needs and demands to a great extent due to the fact that they are not context-specific and can not be applied and implemented in all local teaching contexts (Kumaravadivelu, 1994). In this way, Kumaravadivelu underemphasizes the pedagogical values associated with the individual methods in the broad context of language teaching and asserts that the method era has come to an end and the search for an alternative method is of no avail. In the same vein, some other researchers (e.g., Bax, 2003; Jarvis \& Atsilarat, 2004) have likewise endorsed the inadequacy of CLT and TBLT in addressing broad contextual issues and have called for a context approach to language teaching. In this regard, three decades ago, Richards (1987) rightly believes that language teaching profession should go beyond teaching methodologies and focus on exploring the nature and conditions of effective teaching and learning. This crucial suggestion was later germinated and crystallized in the framework of post-method pedagogy.

According to Kumaravadivelu (2001), teaching beyond methods has led to a focus on the process of learning and teaching, rather than ascribing a central role to methods as the key to successful teaching. To elucidate the underpinning tenets of post-method pedagogy, Kumaravadivelu discusses that

Post-method pedagogy must a) facilitate the advancement of a context-sensitive language education based on a true understanding of local linguistic, sociocultural, and political particularities; (b) rupture the reified role relationship between theorists and practitioners by enabling teachers to construct their own theory of practice; and (c) also tap the sociopolitical consciousness that participants bring with them (p. 537).

Kumaravadivelu (2003b) maintains that post-method pedagogy comprises a three-dimensional system including three pedagogical parameters of particularity, practicality, and possibility. These parameters "interact with each other in a synergic relationship where the whole is greater than the sum of its parts" (p. 545). At its core, any post-method 
pedagogy has to be pedagogy of particularity. That is to say, it must be "sensitive to a particular group of teachers teaching a particular group of learners pursuing a particular set of goals within a particular institutional context embedded in a particular sociocultural milieu ... all pedagogy, like all politics, is local. To ignore local exigencies is to ignore lived experiences" (Kumaravadivelu, 2001, p. 538). To phrase in another word, such pedagogy is "responsive to and responsible for local individual, institutional, social, and cultural contexts in which learning and teaching take place" (Kumaravadivelu, 2003b, p. 544). In summary, pedagogy of practicality aims for a teacher-generated theory of practice. This assertion hinges on a rather simple and straightforward proposition: No theory of practice can be useful and usable unless it is generated through practice (Kumaravadivelu, 2001). And, the parameter of possibility "seeks to empower classroom participants so that they can critically reflect on the social and historical conditions contributing to create the cultural forms and interested knowledge they encounter in their lives" (Kumaravadivelu, 2003b, p. 544).

Additionally, there seems to be another perceptible vexing ecological perspective within this approach which can substantially influence or even constrain the implementation of ELT methodology. In this regard, methodologies and teaching materials, especially those originating in the West, have been severely criticized for embodying politically and culturally imperialist stance which has permeated in the domain of second language pedagogy and has dramatically undermined the process of language learning and teaching accordingly (see Pennycook, 1989; Phillipson, 1992, 2009 for further details and also see Pishghadam \& Zabihi, 2012 for some recent innovations). In this sense, Sampson (1984) points to the fallacious assumption of technocratic imperialism. Through the biased lens of this imperialism, everything exported from developed countries to developing countries is superior and intellectual goods such as teaching methods and materials are value-free and therefore universally appropriate. In this respect, Holliday (1994, p. 175), for example, asserts that "learner-centeredness carries with it a set of perhaps naive ideas which belong to the BANA (British, Australian, North American) professional-academic culture which provide a banner for the moral superiority of the communicative approach" (as cited in Larsen-Freeman, 1999).

In a similar vein of argument, Kumaravadivelu (2003b) addresses the emergences of colonialism in the prevailing language teaching methods and argues that "the methods used in different parts of the world, however modified they are, still basically adhere to the colonial concept of method"(p. 541). In view of such colonial phenomenon, Kumaravadivelu maintains that the concept of method can be viewed from its four inter-related dimensions, that is, scholastic, linguistic, cultural, and economic perspectives. In an effort to deal with this postcolonial crisis, Kumaravadivelu proposes a bottom-up processing framework called macrostrategic framework. This framework consists of both macrostrategies and microstrategies derived from theoretical, empirical and experimental insights to second/foreign language learning and teaching. It is a broad guideline based on which teachers are able to generate their own situation-specific or need-based classroom techniques (see Kumaravadivelu, 2003b for description of the 10 micro/macrostrategies). Within this postcolonial project, practitioners of post-method pedagogy are cautioned against two deleterious dimensions of the post-method predicament, namely the process of marginalization and the practice of self-marginalization (see also Kumaravadivelu, 2003b for subtle influence of these two domination-subordination agents). However, in terms of the critiques of post-method paradigm, Tajeddin (2005) contends that "while being a consequence of the general trend of paradigm shift, the post-method paradigm is founded on a number of premises still prevalent in the method era" (p. 1). There are also further similar dissenting voices; for instance, Larsen-Freeman (2005) and Liu (1995) argue that post-method is not an alternative to 'method' but only an addition to 'method'.

\section{B. 'In-method' Approach}

Given the well-documented studies which have indicated the observed mismatches between CLT principles and the practical applicability of its methodology in different teaching contexts, researchers began to focus on the cultural appropriateness of the methodologies in the given contexts. Within this approach, the notion of ethno-methodological appropriateness is mainly emphasized, whereas the steadfast pedagogical values of ELT methods are still recognized. As such, methods are valuable when they are used sensitively, sensibly, and inquiringly (Holliday, 1994; LarsenFreeman, 1999). Furthermore, Larsen-Freeman (2000) questions the position of absolutism in ELT methodology which claims that one single method is best in the area of language pedagogy. As an alternative to this position, she advocates two other related positions, namely, relativism and pluralism. The former position states that methods have their own weaknesses and strengths and thus are not equally suited for all teaching contexts. The latter position calls for the synthesis of different methods and contends that there is still some value to each method. In this sense, "rather than adopting or rejecting methods in their entirety as being suitable or unsuitable for a particular context, different methods, or parts of methods should be practiced in the same teaching context" (Larsen-Freeman, 2000, p. 182).

Furthermore, a growing body of criticisms have drawn attention to these methodology-related problems during the last two decades, claiming that there can be no one best method (e.g. Bartolome, 1994) because a method which is suitable in one part of the world is not necessarily appropriate for all parts of the world. In view of this methodological crisis, some research studies have yielded similar confirming insights for CLT approaches (e.g. Chowdhury, 2003; Ellis, 1994; Hu, 2002; Nishino, 2008; Savignon \& Wang, 2003; Stapleton, 1995; Wu \& Fang, 2002). In effect, the methodological challenges reported within CLT approaches indicate that although CLT is perceived as progressive and efficient in some parts of the world, it is not seen as an appropriate way to teach languages everywhere, since many of its underpinning values conflict with those of other cultures (Larsen-Freeman, 1999).

The Reconciliation of Language Pedagogy with ELT Methods 
One of the main proponents of the 'In-method' approach who has attempted to raise the reconciliation of language pedagogy with ELT methods is Larsen-Freeman (1999). In fact, she revitalizes the intrinsic value of 'method' itself and disapproves of the emergence of post-method era in second language teaching. In defense of the overlooked aspects of ELT methods, Larsen-Freeman argues that discarding the crucial merits of methods is only a misconception and it is a pity that post-method teaching is the final response to the SLT Dilemma. On the contrary, she truly believes that methods can still serve language teaching substantially. In attempting to be culturally appropriate, Larsen-Freeman (1999) asserts that methods must not be considered a priori as appropriate or inappropriate to any given teaching contexts, since they can contribute to the de-skilling of language teachers. Indeed, she believes that "assuming that teachers are helpless victims of ideological imposition and disregarding their agency in the teaching/learning process seems just as much an affront as assuming that new methodologies are superior to traditional ones" (p. 26). According to Larsen-Freeman, the main reason for methodological failures lies in the fact the proposed methods have been imposed on teachers by others and are not going to be shaped by teachers' own knowledge, beliefs, and expertise.

Given the ecological challenges in the landscape of ELT methodology, Larsen-Freeman (1999) discusses that the key to resolve these constrains is moving beyond ideology to inquiry, a way which can avoid the inappropriate uses of methods, while benefiting from them at the same time. To elaborate on her proposal, then she introduces the notion of seven "I's" - moving beyond Ideology to Inquiry while challenging the methodological myths of Inclusive generalizations, Intactness and Immutability, and the false assumption that Imposition leads to Implementation.. In line with Larsen-Freeman's reaction to the ecological constraints in question, Holliday (1999) stresses the significance of individual differences and similarly argues that a large culture approach (by large he means ethnic and national entities) results in reductionist overgeneralizations of foreign educators, students, and societies. According to Holliday, one can not determine the appropriateness of a particular methodology on the basis of cultural stereotypes. Instead, it must be decided by politically and individually-sensitive local educators.

According to Prabhu (1990), methods are not just empty vehicles delivering language content. That is, by inquiring into their practice via interacting with other ideologies, it helps keep teachers' teaching alive and prevent it from becoming stale and overly routinized. In fact, methods are by no means superimposed on language teaching and can be crystallized differently nonetheless due to both contextual differences and teachers' stage of development (LarsenFreeman, 1999). According to Larsen-Freeman, teachers can borrow the techniques of a method ad hoc, without its accompanying values because teachers must not only develop their thoughts about teaching, but also their actions or techniques. To meet the aims of the study, the researcher here manifests how ecological constraints of language pedagogy are viewed and dealt with within another related groundbreaking approach called Complexity approach.

\section{Complexity Approach}

Generally what makes Complexity approach so attractive and useful for scientists is attributable to its ways of unraveling the mystery of what appears to be pure randomness. As such, it gives a new perspective demonstrating the existence of deeper explanation for the multi-faceted world in which we live. In this approach, the questions related to natural systems that have been discarded because of appearing to be unsolvable have also begun to be answered. By definition, complex systems are composed of multiple agents that interact with and adapt to one another and the environment while co-evolving and self-organizing without any central control (Kauffman, 1993, 1995). However, in applied linguistics, researchers usually do not draw a distinction between chaos and complexity referring to them as chaos/complexity (see Larsen-Freeman, 1997; Larsen-Freeman \& Cameron 2008a). As Mallows (2002) remarks, "chaos is understood in an interestingly paradoxical way as order without predictability. We cannot predict individual moments in the life of a system, but the end results of its seemingly random movement are discernable order" (p. 3).

According to Larsen-Freeman (1997), chaos/complexity scientists have identified a number of describing features of complex systems. The main features of these complex systems are known to be "dynamic, nonlinear, chaotic, unpredictable, sensitive to initial conditions, open, self-organizing, feedback sensitive and adaptive" (p. 142). Within this approach, Larsen-Freeman considers ecology as a complex network of interacting organisms which leads to theory building that learns from complexity science and chaos theory. To clarify the characteristics of chaos in this theory, McAndrew (1997) also assigns three features to this concept: "a) chaos is characterized by a sensitive dependence on initial conditions or what has become known as the butterfly effect; b) chaotic system is aperiodic or never undergoes a regular repetition of values: no repeat system; c) strange attractors (attract and repel)" (p. 39). However, the present study does not intend to overview all aspects of chaos/complexity paradigm in its entirety. Instead, it focuses on its ecological aspects to illustrate how the ecological challenges of language teaching are dealt with within this approach.

\section{Complexity and Second Language Teaching (SLT)}

By virtue of this approach, ecological challenges of language teaching are addressed in a more broad sense which is virtually beyond the scope of the Post-method and 'In-method' approach. Drawing on the prevailing emergence of complexity paradigm in some social sciences, there seems to be a relatively recent line of research acknowledging the multidimensional aspects of non-linearity and complexity sustaining in SLA and SLT (Cameron, 1999; De Bot, Lowie \& Verspoor, 2005; Hadidi Tamjid, 2008; Hodge, 2003; Larsen-Freeman, 1997, 2007; Larsen-Freeman \& Cameron, 2008b). However, Larsen-Freeman (1997) was the first SLA researcher who pointed out the emergence of complexity paradigm in SLA and ushered in new directions in thinking about language learning processes. Larsen-Freeman (2002) argues that the chaos/ complexity theory advocates a social participation view of SLA without excluding the 
psycholinguistic perspective. In holding learner and context as inseparable, one of the visible discrepancies between this approach and the Post-method and 'In-method' approach is that this approach emphasizes the importance of adopting an 'all-inclusive perspective'. That is, viewing language learner and complex teaching context as unpredictably co-evolving and co-adaptive dynamic (sub) systems nested within other interacting complex systems.

In terms of second language pedagogy, several researchers have also concluded that classroom practices can be manifested in a relatively predictable manner as far as only linear teaching methods are involved. That is, when unforeseen and unidentified factors have an unpredictable impact, the classrooms and the participants in them are in a state of flux and thus linear cause and effect descriptions cannot comprehensively account for the possible pedagogical constraints in the classrooms (see Burns \& Knox, 2011; Finch, 2001; Hodge, 2003; Tudor, 2001). In this sense, a live language learning acquisition system seems to be always in flux and never reaches equilibrium, although it undergoes period of stagnation and anarchy called the edge of chaos (see Waldrop, 1993 for further characteristics of the edge of chaos) in which maximum learning can occur. In fact, these periods are considered as phases of maximum creativity where the systems operate between order and chaos/ randomness and attempt to bring them into a special kind of balance via the emergence of new attractors. Attractors refer to "states or particular modes of behaviors, which the system prefers" (Larsen-Freeman \& Cameron, 2008a, p. 49). Considering the teaching context as the initial condition of second language teaching, it can also be argued that ecological challenges faced by teachers and learners such as the examples of the ecologically-oriented constrains of ELT methodology mentioned earlier may lead to the creation of the edge of chaos in the learning systems of learners, exhibiting a new linguistic behavior or attractor accordingly.

By the same token, other researchers have likewise examined language classrooms from ecological perspectives within this approach, (see Kramsch, 2002; Van Lier, 1997, 2000, 2004). For example, Van Lier (1997) argues that by adopting an ecological perspective on observation of learning, we can focus on the complex processes of interactions and unravel them from the inside out, in all their complexity. However, given the ecological challenges of second language teaching, the influential studies of Tudor $(1998,2003)$ are perhaps among the exceptions.

With respect to resolving these ecological challenges, first Tudor (1998) proposes the concept of rationality and cautions against the vexing perception of rationality in language teaching in which it is fallaciously treated as a discrete set of principles used to guide decision making in an objective, linear and generally applicable manner. According to Tudor, this view ignores the reality that language teaching is construed as the dynamic interaction of different rationalities involved in the given teaching contexts which is unique to each classroom and can rarely be predicted in advance. In this sense, Tudor also introduces the idea of contextual negotiation to deal with the possible ecological constrains. The idea of contextual negotiation incorporates the ideologies from student rationality, teacher rationality, methodological rationality, and socio-cultural rationality. Considering language teaching as contextual negotiation, Tudor (2002) asserts that context is a complex phenomenon which entails the negotiation of its two main components, namely, pragmatic and mental. "The pragmatic context of teaching relates to the objectively observable features of the language teaching situation ...The mental context of teaching arises out of the attitudes, beliefs, behavioral expectations, goals and aspirations which participants bring with them to the classroom" (pp. 1-2).

On the other hand, however, a few critics of the complex view of language learning (see, for instance, Benson \& Hunter, 1993) have purported that since learning is so chaotic and unpredictable; teaching can not be sufficiently sustained and must therefore be of no avail. In response to this fallacious assumption, Harshbarger (2007) argues that complex system behaviors are not entirely random and unfathomable. In the light of such idea, Harshbarger considers the natural phenomenon of hurricane as a metaphorical example to explain this issue. He states that "a hurricane is a complex system that can't be directly controlled, but contextual influences such as prevailing winds and temperature differentials over land and water produce tendencies that guide these storms to move and develop in roughly predictable ways" (p. 12). In defense of the complexity paradigm in the area of second language teaching, he also asserts that the complexity perspective is not inimical to any method or approach. In this respect, he also maintains that

Language learning and teaching is complex enough that learners may (at times) benefit from deductive, drill-based learning as well as inductive, task-based activities. Learning and learners are not amenable to a best method, a best book, a best test, or a best curriculum. Learners are most amenable to influences that recognize, respond to, and nurture their truly complex and dynamic learning processes (p. 14).

However, it is safe to mention that despite the fact that a few clear-cut fledging schemes and models of language learning and teaching based on complexity paradigm have been formulated (e.g. Burn \& Knox, 2011; Harshbarger, 2007; Kymes, 2007; Larsen-Freeman \& Cameron, 2008b), seemingly the lack of a well-established model derived from a complexity paradigm including some practical organizing principles for ELT practitioners to resolve the ecological challenges in a sufficiently systematic manner is still evident in the area of second language pedagogy.

\section{DISCUSSION}

In the current study, a quick state-of-the-art overview of the classified theoretical trends in relation to ecological challenges of language teaching suggests that, on the one hand, there seems to be certain symmetry in the rationales behind the approaches under study. To epitomize metaphorically this perceptible commonality, it can be argued that these evolving alternatives have called for a more tentatively localized remedy rather than a spoon-fed panacea which at once fits all teaching contexts. In principle, over the last few decades, these approaches have unanimously underscored 
the significance of localness and context-sensitivity of language teaching. Thus, it can be implied that these approaches ought to be regarded as complementing each other, rather than as competing with each other for absolute supremacy. Yet what distinguishes these approaches can be found in their scope of viewing and settling the subject of dispute.

In short, Post-method approach devalues the pedagogical effectiveness of ELT methods and necessitates the openended pedagogy beyond the restricted boundary of alternative ELT methods in which the ecological constraints of specific teaching contexts can thus be identified and resolved. In this approach, it is posited that since the pervious methods have been developed based on a set of generalized tenets, they are not context-specific and can not be applied and implemented in all local teaching contexts. In contrast to this approach, 'In-method' approach revalidates the neglected merits of ELT methods and attempts to reconcile language pedagogy with ELT methods. Overall, the notion of ethno-methodological appropriateness is emphasized in this approach, and the socio-cultural constraints are also considered and tackled within the domain of 'method' itself.

The final voice emanates from Complexity approach in which the ecological challenges are seen beyond the scope of the Post-method and 'In-method' approach, since it is assumed the proposed solutions can not thoroughly resolve this contentious issue. In the light of such approach, it is also believed that the pursuit of settling the ecological challenges of SLT Dilemma must not be considered pointless. Instead, it is suggested that the other two developed approaches discussed here are not only mutually exclusive, but also have complemented each other to come up with a deeper understanding of the various ecological aspects of language learning and teaching. As a result, they can both contribute to diminish the vexing ecological impediments surrounding individual teaching contexts with which the involved participants are dynamically interacted. However, the Complexity approach also argues that the Post-method and 'Inmethod' approach have not been able to thoroughly resolve the ecological challenges of SLT Dilemma due to the fact that they have virtually not paid sufficient attention to the complexity of language learning and teaching and have not approached the ecological aspects of SLT Dilemma from within the avenue of complexity paradigm.

\section{CONCLUSION}

In conclusion, to broaden our horizons towards understanding the genesis and causes of the widespread ecological challenges of SLT Dilemma, the author, however, truly approves of Complexity approach more than the other two alternatives because the intricate effects of ecological variables can be discerned and studied in a more optimal manner. Nevertheless, to approach and disentangle the enigma of ecological barriers in a sufficiently systematic manner within this approach seems to entail a well-established feasible model of second language teaching. This realizable model will need to comply with the complexity paradigm and also include some practical guiding principles for ELT teachers. Until such well-established model is proposed, the author calls for a 'relativism perspective' to solve the ecological challenges at the present time. This perspective explains that there is almost little gain in adopting exclusively only one of the three approaches because some of their premises are notably interdependent while none of the current approaches is also pedagogically self-contained now and can not individually tackle the ecological challenges. For example, the pedagogical premises and practical guidelines visualized in the Post-method and 'In-method' approach are not clearly seen in the Complexity approach. In the light of this perspective, ecological challenges of language teaching might be envisaged from a vantage point in which they can be alleviated to a varying degree depending on the given teaching contexts. But they can not be avoided entirely due to the dynamic ecologies of interrelated and interdependent complex systems which can be partially or temporarily controlled and predicted. All in all, henceforth what seems to lie ahead is the essentials of learning to co-exist with these ever-evolving ecological challenges, rather than merely attempt to find a way to dispense with them. By learning to live within the realm of these challenges, it is perhaps more likely that our research-based pedagogical enterprise will ultimately yield some promising inbuilt solutions.

\section{REFERENCES}

[1] Allwright, R. L. (2003). Exploratory practice: Rethinking practitioner research in language teaching. Language Teaching Research, 7(2), 113-141.

[2] Bartolome, L. (1994). Beyond the methods fetish: Toward a humanizing pedagogy. Harvard Educational Review, 64(2), 173194.

[3] Bax, S. (2003). The end of CLT: A context approach to language teaching. ELT Journal, 57(3), 278-287.

[4] Benson, G. \& Hunter, W. (1993). Chaos theory: No strange attractor in teacher education. Action in Teacher Education 14, 6169.

[5] Bjorning-Gyde, M., Doogan, F., \& East, M. (2008). Towards a fusion model for the teaching and learning of English in a Chinese context. In M. Wallace \& L. Dunn (Eds.), Teaching in transnational higher education: Enhancing learning for offshore international students (pp. 77-87). New York: Routledge.

[6] Breen, P. (2006). The education of language teachers in East Asia. Asian EFL Journal, 4(4). Retrieved May 13, 2007 from http://www.asian-efl-journal.com/pta_july_06_pb.php

[7] Burns, A, \& Knox, J.S. (2011). Classrooms as complex adaptive systems: A relational model. TESL-EJ, 15(1), 1-25. Retrieved September 8, 2011 from http://www.tesl-ej.org/wordpress/issues/volume15/ej57/ej57a1/

[8] Butler, Y. G. (2005). Comparative perspectives towards communicative activities among elementary school teachers in South Korea, Japan and Taiwan. Language Teaching Research, 9(4), 423-446. 
[9] Cameron, L. (1999). The complex dynamics of language use on tasks. Paper presented at the British Association for Applied Linguistics Annual Meeting, University of Edinburgh. Retrieved July 16, 2010 from http://www.education.leeds.ac.uk/research/ljc_complang.pdf

[10] Chowdhury, R. (2003). International TESOL training and EFL contexts: The cultural disillusionment factor. Australian Journal of Education, 47(3), 283-302.

[11] Danesi, M. (2003). Second language teaching: A view from the right side of the brain. The Netherlands: Kluwer Academic Publishers.

[12] De Bot, K., Lowie, W., \& Verspoor, M. (2005). Second language acquisition: An advanced resource book. London: Routledge.

[13] Ellis, G. (1994). How culturally appropriate is the communicative approach? ELT Journal, 50(3), 213-218.

[14] Ellis, R. (2005). Instructed second language acquisition: A literature review. Wellington, New Zealand: New Zealand Ministry of Education. $\quad$ Retrieved $\quad$ December $\quad 11, \quad 2008$ from http://www.educationcounts.govt.nz/data/assets/pdf_file/0008/6983/instructed-second-anguage.pdf

[15] Fenton, A. L., \& Terasawa, Y. (2006). Paradigm lost? A belated reply to Jarvis and Atsilarat from Japan. Asian EFL Journal, 4(4), 219-237. Retrieved December 15, 2007 from http://www.asian-efl-journal.com/March_06_af\&yt.php

[16] Finch, A. (2001). Complexity in the classroom. Secondary Education Research, 47, 105-140. Retrieved May 14, 2011 from http://www.finchpark.com/arts/

[17] Hadidi Tamjid, N. (2008). Chaos/ complexity theory in second language acquisition. Novitas-Royal, 1(1), 10-17.

[18] Harshbarger, B. (2007). Chaos, complexity and language learning. Language Research Bulletin, 22. Retrieved March 13, 2010 from http://www.scribd.com/doc/3017595/Chaos-Complexity-and- Language-Learning

[19] Hodge, R. (2003). Chaos theory: An introduction for TESOL practitioners. English Australia (EA) Journal, 21(1), 8-16.

[20] Holliday, A. (1994). Appropriate methodology and social context. Cambridge: Cambridge University Press.

[21] Holliday, A. (1999). Small cultures. Applied Linguistics, 20(2), 237-264.

[22] Howard \& Millar. (2009). The applicability of principles for instructed second language learning: A South Korean perspective. Asian EFL Journal, 11(4), 31-57.

[23] Hu, G. (2002). Potential cultural resistance to pedagogical imports: The case of communicative language teaching in China. Language, Culture and Curriculum, 15(2), 93-105.

[24] Hu, G. (2005). Contextual influences on instructional practices: A Chinese case for an ecological approach to ELT. TESOL Quarterly, 39(4), 635-660.

[25] Jarvis, H., \& Atsilarat, S. (2004). Shifting paradigms: From a communicative to a context-based approach. Asian EFL Journal, 6(4). Retrieved December 14, 2007 from http://www.asian-efl-journal.com/december_04_HJ\&SA.php

[26] Johnson, K. (2006). The sociocultural turn and its challenges for second language teacher education. TESOL Quarterly, 4O(1), $235-252$.

[27] Kauffman, S. (1993). The origins of order: self-organization and selection in evolution. New York: Oxford University Press.

[28] Kauffman, S. (1995). At home in the universe: the search for the laws of self-organization and complexity. New York: Oxford University Press.

[29] Kramsch, C. (Ed.). (2002). Language acquisition and language socialization: Ecological perspectives. London: Continuum.

[30] Kumaravadivelu, B. (1994). The postmethod condition: (E)merging strategies for second/foreign language teaching. TESOL Quarterly, 28, 27-48.

[31] Kumaravadivelu, B. (2001). Towards a postmethod pedagogy. TESOL Quarterly, 35(4), 537-559.

[32] Kumaravadivelu, B. (2003a). Beyond methods: Macrostrategies for language teaching. New Haven, CT: Yale University Press.

[33] Kumaravadivelu, B. (2003b). Critical language pedagogy: A post-method perspective on English language teaching, World Englishes, 22(4), 539-550.

[34] Kumaravadivelu, B. (2006a). TESOL methods: Changing tracks, challenging trends. TESOL Quarterly, 40(1), 59-81.

[35] Kumaravadivelu, B. (2006b). Understanding language teaching: From method to postmethod. Mahwah, NJ.: Lawrence Erlbaum.

[36] Kymes, A. (2007). Chaos, complexity, curriculum, and culture: A conversation (Book Review). Curriculum and Teaching Dialogue, 9, 327-330.

[37] Larsen-Freeman, D. (1997). Chaos/complexity science and second language acquisition. Applied Linguistics, 18(2), $141-165$.

[38] Larsen-Freeman, D. (1999, October). On the appropriateness of language teaching methods in language and development. Paper presented at the Fourth International Conference on Language and Development, Hanoi. Retrieved October3, 2010 from http://www.languages.ait.ac.th/hanoi_proceedings/ larsen-freeman.htm.

[39] Larsen-Freeman, D. (2000). Techniques and principles in language teaching (2nd ed.). Oxford, England: Oxford University Press.

[40] Larsen-Freeman, D. (2002). Language acquisition and language use from a chaos/complexity theory perspective. In C. Kramsch (Ed.), Language acquisition and socialization (pp. 33-46). London: Continuum International Publishing Group.

[41] Larsen-Freeman, D. (2005). A critical analysis of postmethod. ILI Language Teaching Journal, 1, $21-25$.

[42] Larsen-Freeman, D. (2007). On the complementarily of chaos/complexity theory and dynamic systems theory in understanding the second language acquisition process. Bilingualism: Language and Cognition, 10(1), 35-37.

[43] Larsen-Freeman, D. \& Cameron, L. (2008a). Complex systems and applied linguistics. Oxford: Oxford University Press.

[44] Larsen-Freeman, D. \& Cameron, L. (2008b). Research methodology on language development from a complex systems perspective. The Modern Language Journal, 92, 200-213.

[45] Li, D. (1998). "It is always more difficult than you plan and imagine": Teachers' perceived difficulties in introducing the communicative approach in South Korea. TESOL Quarterly, 32(4), 677-708.

[46] Lightbown, P. M. (2000). Anniversary article: Classroom SLA research and second language teaching. Applied Linguistics, 21(4), 431-462.

[47] Liu, D. (1995). Comments on B. Kumaravdivelu's "The postmethod condition: (E)merging strategies for second/foreign language teaching": "Alternative to" or "addition to" method? TESOL Quarterly, 29, 174-177. 
[48] Mahmoodzadeh, M. (2011). The quest for resolving second language teaching dilemma: A review of the proposed solutions during the last two decades. Theory and Practice in Language Studies, 1(10), 1375-1382.

[49] Mahmoodzadeh, M. (2012). The study of principles and techniques of bimodality theory from ELT teachers' perspective: The case of Iranian teachers. Iranian EFL Journal, 8(1), 183-207.

[50] Mallows, D. (2002). Non-linearity and the observed lesson. ELT Journal, 56(1), 3-10.

[51] McAndrew, D. A. (1997). Chaos, complexity, and fuzziness: Science looks at teaching English. English Journal, 86(7), 37-43.

[52] Nishino, T. (2008). Japanese secondary school teachers' beliefs and practices regarding communicative language teaching: An exploratory survey. JALT Journal, 30(1), 27-50.

[53] Pennycook, A. (1989). The concept of method, interested knowledge, and the politics of language teaching. TESOL Quarterly, 23(4), 591-615.

[54] Phillipson, R. (1992). Linguistic imperialism. Oxford: Oxford University Press.

[55] Phillipson, R. (2009). Linguistic imperialism continued. NY \& London: Routledge.

[56] Pishghadam, R. (2011). Introducing Applied ELT as a new approach in second/foreign language studies. Iranian EFL Journal, 7(2), 8-14.

[57] Pishghadam, R. \& Zabihi, R. (2012). Applied ELT as a panacea for linguistic imperialism. Iranian EFL Journal, 8(1), 35-52.

[58] Pishghadam, R. \& Zabihi, R. (in press). English language teaching as change: Introducing and exemplifying English for Life Purposes (ELP). Education as Change: Journal of Curriculum Research.

[59] Prahbu, N. S. (1990). There is no best method - Why? TESOL Quarterly, 24(2), 161-176.

[60] Richards, J. C. (1987). Beyond methods: Alternative approaches to instructional design in language teaching. Prospect, 3(1), 11-30.

[61] Richards, J. C. (1990). The language teaching matrix. Cambridge: Cambridge University Press.

[62] Richards, J. C. (2001). Beyond methods. In D. Hall \& A. Hewings (Eds.), Innovations in English language teaching (pp. 167179). London: Routledge.

[63] Richards, J. C. (2002). 30 years of TEFL/TESL: A personal reflection. RELC Journal, 33(2), 1-35.

[64] Richards, J. C. \& Lockhart, C. (1994). Reflective teaching in second language classrooms. New York: Cambridge University Press.

[65] Sampson, G. (1984). Exporting language teaching methods from Canada to China. TESL Canada Journal, 1(1), 19-31.

[66] Savignon, S., \& Wang, C. (2003). Communicative language teaching in EFL contexts: Learner attitudes and perceptions. International Review of Applied Linguistics in Language Teaching, 41(3), 223-249.

[67] Shamim, F. (1996). Learner resistance to innovation in classroom methodology. In H. Coleman (Ed.), Society and the language classroom (pp. 105-121). Cambridge, England: Cambridge University Press.

[68] Stapleton, P. (1995). The role of Confucianism in Japanese education. The Language Teacher, 19(4), 13-16.

[69] Stern, H. H. (1991). Fundamental concepts of language teaching. Oxford: Oxford University Press.

[70] Tajeddin, Z. (2005). A critique of the inception and premises of the postmethod paradigm. ILI Language Teaching Journal, $1(1), 1-14$.

[71] Tudor, I. (1998). Rationality and rationalities in language teaching. System, 26, 319-334.

[72] Tudor, I. (2001). The dynamics of the language classroom. Cambridge: Cambridge University Press.

[73] Tudor, I. (2002). Exploring context: Localness and the role of ethnography. Humanising Language Teaching, 4(2), 1-7. Retrieved May 11, 2011 from http://www.hltmag.co.uk/mar02/mart11

[74] Tudor, I. (2003). Learning to live with complexity: towards an ecological perspective on language teaching. System, 31, 1-12.

[75] Van Lier, L. (1997). Observation from an ecological perspective. TESOL Quarterly, 31(4), 783-787.

[76] Van Lier, L. (2000). From input to affordance: Social-interactive learning from an ecological perspective. In J. P. Lantolf (Ed.), Sociocultural theory and second language learning: recent advances (pp. 245-259). Oxford: Oxford University Press.

[77] Van Lier, L. (2004). The ecology and semiotics of language learning: A sociocultural perspective. New York: Kluwer Academic Publishers.

[78] Waldrop, M. M. (1993). Complexity: The emerging science at the edge of order and chaos. New York: Touchstone.

[79] Wu, X., \& Fang, L. (2002). Teaching communicative English in China: A case study of the gap between teachers' views and practice. Asian Journal of English Language Teaching, 12, 143-162.

[80] Yu, L. (2001). Communicative language teaching in China: Progress and resistance. TESOL Quarterly, 35, 194-198.

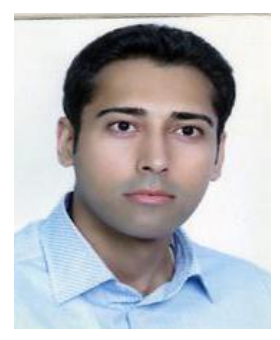

Masoud Mahmoodzadeh holds an M.A. degree in TEFL from Sheikhbahaee University, Isfahan. As a young researcher, his research studies have contributed to some professional peer-reviewed local and international journals such as Iranian EFL Journal, Theory and Practice in Language Studies, and Journal of Language Teaching and Research. His main areas of interest include second language acquisition, language teaching methodology, curriculum planning/evaluation, and the role of affective variables in language teaching, especially foreign language anxiety. 